\title{
Os protestos estudantis de 2013 e os movimentos sociais no Brasil contemporâneo
}

Angelo Girotto Neto

Resumo: Os protestos de 2013 seguem fomentando produtivos debates acerca da realidade política do Brasil contemporâneo. Este artigo busca entender suas motivações e particularidades, valendo-se de uma revisão crítica de importantes teóricos das Ciências Socais, notadamente Manuel Castells. Propõe- se que a horizontalidade e a ausência de lideranças estabelecidas engendraram uma mobilização política mais participativa, mastambém corroboraram com os esforços da grande mídia em dirigir os rumos dos movimentos.
Palavras-chave:
Movimentos
sociais.
Política
brasileira.
Movimentos de junho de 2013.

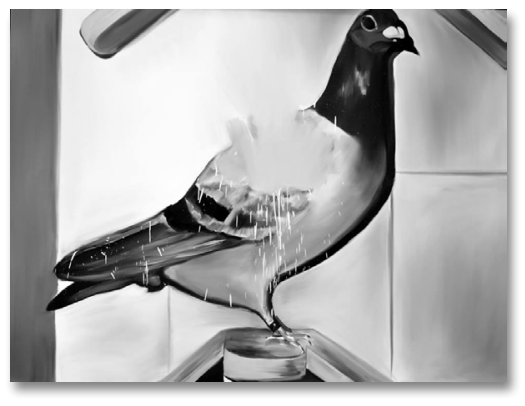

\section{The 2013 student protests and the social movements in contemporary Brazil}

Abstract: The protests of 2013 continue to foment productive debates about the political reality of contemporary Brazil. Drawing upon a critical review of important social science theorists, notably Manuel Castells, this article seeks to understand the motivations and particularities, of the protests. It is proposed that the horizontality and absence of established leaderships engendered a more participatory political

\section{$\overline{\text { Angelo Girotto Neto }}$}

Mestre em Ciências Sociais pelo Programa de Pós-Graduação em Ciências Sociais da Universidade Federal do Rio Grande do Norte (UFRN).

angelogirotto@gmail.com mobilization but also supported the efforts of the mainstream media to direct the course of the social movements.

Keywords: Social movements. Brazilian politics. June 2013 Movements.

$$
\begin{array}{r}
\text { RECEBIDO 22.12.2015 } \\
\text { APROVADO 16.04.2016 }
\end{array}
$$




\section{INTRODUÇÃO: OS MOVIMENTOS ESTUDANTIS DE $2013^{1}$}

Da noite para o dia, milhões de brasileiros foram atordoados por imagens de uma brutal violência contra manifestantes num protesto na capital paulista; imagens que foram veiculadas à exaustão pela imprensa televisiva, no dia 13 de junho de 2013, e também nas redes sociais e nos grandes portais da internet. Nas semanas subsequentes, uma onda de manifestações com proporções inesperadas varreu o país. Observadores se viram sem compreender aquilo a que muitos chamaram de "a voz das ruas". As três esferas do poder estatal se apressaram em dar respostas. Já no dia 21 de junho, a ex-presidente Dilma Rousseff - em pronunciamento à Nação - disse ter "a obrigação de ouvir a vOz das ruas" (ROUSSEFF, 2013). Manuel Castells, sociólogo espanhol, cujas teses sobre os movimentos internacionais dos últimos anos debateremos, declarou em entrevista que "Dilma é a primeira líder mundial a ouvir as ruas" (ROUSSEFF, 2013).

Foi a cidade de São Paulo o estopim da Grande Onda² e é nela que se concentrará a exposição do primeiro momento dos Movimentos de Junho. Os movimentos estudantis de 2013, nos termos deste estudo, se estenderam até o dia 13 de junho daquele ano, na capital paulista. Entraram em sua fase principal de mobilização após o anúncio conjunto do prefeito paulistano e do governador paulista, Fernando Haddad e Geraldo Alckmin, do aumento das passagens de ônibus, trens e metrôs no dia 17 de maio. O reajuste vigoraria a partir de 2 de junho, quando as passagens passariam a custar $\mathrm{R} \$ 3,20$.

1 Este artigo é um extrato das análises que resultaram na dissertação $A$ voz das ruas e a rearticulação da ideologia conservadora, desenvolvida no âmbito do Programa de Pós-Graduação em Ciências Sociais da Universidade Federal do Rio Grande do Norte, sob orientação do Prof. Dr. José Antônio Spinelli, a quem o autor agradece pela irrestrita generosidade.

$2 \mathrm{O}$ período identificado como Grande Onda corresponde às semanas imediatamente posteriores ao 13 de junho de 2013. Nele, ocorreram protestos com dezenas de milhares de pessoas, a exemplo de São Paulo que apresentou o seguinte quadro de mobilização nas duas primeiras semanas: 65 mil manifestantes no protesto de 17 de junho; 50 mil em 18 de junho; 100 mil em 20 de junho; e 35 mil em 22 de junho. As pautas se diversificaram, abarcando desde reivindicações concernentes à ampliação do acesso e da qualidade dos serviços públicos, até o descontentamento com os gastos na Copa do Mundo de 2014 e a denúncia da corrupção pública. Sua mobilização não se dava mais prioritariamente pelas redes de movimentos sociais e estudantis, mas sim através da imprensa, sobretudo a televisão, e de redes sociais da internet, de forma difusa. 
Segundo o censo do IBGE de 2010, a cidade de São Paulo possuía, então, 11.253.503 habitantes, sendo o núcleo de uma região metropolitana altamente conurbada, cuja população ultrapassava, numa conta rápida, os 20 milhões. O seu sistema integrado de transportes públicos - que compreende ônibus, trens e metrôs - é vítima não só da pressão populacional, como da reconhecida falta de planejamento urbano e da escassez de investimentos.

O transporte público é, há muito, uma questão central na vida de dezenas de milhões de brasileiros que vivem em grandes centros urbanos. A qualidade dos serviços é deplorável, o que emana das manifestações pessoais constantes dos usuários, veiculadas pelas diversas mídias e que motivam uma série de estudos, que são visivelmente mais frequentes a cada dia.

Poucas semanas após sua posse, o então prefeito Haddad anunciou que reajustaria a tarifa de ônibus, que estava congelada, desde janeiro de 2011, em R\$3,00 e cuja defasagem custou aos cofres municipais R 961 milhões em 2012 (PASSAGENS..., 2013). Contudo, conforme o próprio lamento do prefeito através da imprensa, a preocupação do Governo Federal em controlar a ameaça de pressão inflacionária o levou a adiar o aumento até o fim do primeiro semestre.

No Rio de Janeiro, a Prefeitura acompanhou a capital paulista e só realizou o aumento em $1^{\circ}$ de junho, passando de $\mathrm{R} \$ 2,75$ para $\mathrm{R} \$ 2,95$. Em outras capitais, os aumentos já haviam ocorrido ao longo do ano. Belo Horizonte se adiantou a todos e subiu os preços de suas passagens em vinte centavos no dia 29 de dezembro de 2012. Fortaleza fez seu reajuste no mesmo valor, no dia 20 de fevereiro de 2013, passando a passagem de $\mathrm{R} \$ 2$ para $\mathrm{R} \$ 2,20$. Curitiba reajustou em $\mathrm{R} \$ 2,85$ a passagem que custava $\mathrm{R} \$ 2,60$. Recife já havia elevado sua tarifa em vinte centavos, no dia 06 de janeiro. Natal subiu o preço das passagens de $R \$ 2,20$ para $R \$ 2,40$ no dia 18 de maio. O aumento de Porto Alegre, concedido em 25 de março, já havia sido suspenso pela justiça. Ao todo, 14 capitais reajustaram os preços de suas tarifas de transporte público entre dezembro de 2012 e junho de 2013. 
Movimentos estudantis centrados na problemática do transporte público se tornaram parte de um calendário extraoficial de mobilizações anuais, desde a década de 1990, quando a redemocratização e o reconhecimento legal de entidades estudantis como a União Nacional dos Estudantes (UNE) pela Lei Federal 7.398, de 4 de novembro de 1985, no contexto da ascensão de governos neoliberais, impuseram aos movimentos sociais uma agenda de oposição pautada, muitas vezes, pela defesa dos serviços públicos severamente ameaçados de sucateamento.

O próprio Movimento Passe-Livre (MPL), em sua página na internet, apresenta um histórico das suas manifestações, correspondentes aos três aumentos de tarifas mais recentes no município de São Paulo. Os aumentos da última década foram em 2003, 2005, 2006, 2010 e 2011. Cada um desses reajustes teve sua repercussão nos movimentos estudantis, como uma rápida consulta em buscadores e nos sítios eletrônicos de entidades do movimento estudantil pode atestar. Porém, contando normalmente com algumas centenas de manifestantes, quando muito, até junho, os movimentos estudantis de 2013 pouco ou nada conquistaram. Mesmo em capitais como Belo Horizonte e Fortaleza, que chegaram a realizar protestos intensos e em alguns momentos radicalizados, os movimentos estudantis passaram ao largo da preocupação midiática, recebendo seu já tradicional carimbo de "transtornos nas vias públicas".

Em Natal, para dar um exemplo próximo de nossa realidade, a suspensão do sistema de integração de ônibus, que é localmente chamado de Passe Livre, ocasionara, no dia 18 de setembro de 2012, a revolta de cerca de 2 mil pessoas que interditaram um dos principais cruzamentos da cidade (o das avenidas Bernardo Vieira com Salgado Filho). Houve a queima de um ônibus no local e de outro na periferia da cidade. Mais uma vez, as fortes imagens da manifestação contribuíram para que outra ainda maior se realizasse nos dias posteriores, num indicativo de que a violência talvez opere - em certas circunstâncias - como fator de mobilização, sobretudo por atrair a atenção da imprensa (e render boas fotos). Este protesto em Natal teve a liderança parcial de um movimento local similar ao MPL em sua forma de organização e 
seus propósitos políticos. Ainda assim, os protestos eram vistos como localizados, a ênfase da imprensa se dava na baderna e nos transtornos.

Contudo, as coisas estavam por mudar.

No dia posterior à entrada em vigor dos aumentos em São Paulo, o MPL organizou um protesto com algumas dezenas de manifestantes. O objetivo dessa pequena mobilização - que não foi a única, outros atos pequenos e radicalizados se fizeram notar pela cidade no dia 3 de junho - foi a convocação de um grande ato no Vale do Anhangabaú, para o dia 6 de junho.

Quando o protesto do dia 6 chegou à Avenida Paulista, cerca de 2 mil pessoas engrossavam suas fileiras. Diante da tentativa de bloqueio daquela que é uma das mais importantes vias paulistanas, a passeata se viu diante do primeiro ato de uma escalada de violência perpetrada pela Polícia Militar do Estado de São Paulo, cujo ápice se daria no fatídico dia 13 de junho. Desde o dia 3, uma parcela da imprensa já acompanhava atentamente os protestos que, desde o início, renderam fortes imagens de pichações e queima de pneus e depredações de paradas de ônibus, orelhões etc. As cenas de fogo nas ruas, fotos de jovens pintando o asfalto com o dizer "3,20 não" e latas de lixo reviradas, entre outras, logo demonstraram seu apelo ao "fluxo constante de imagens e sons" (GITLIN, 2003, p. 161-164) que constitui a mídia contemporânea, sobretudo a eletrônica. Como já dissemos, o desfecho do ato dia 6 de junho foi o prenúncio do confronto campal da semana seguinte, futuro estopim da Grande Onda. Um portal da internet assim descreveu os acontecimentos:

[...] às $21 \mathrm{~h}$ a Tropa de Choque dispersou os manifestantes, em sua maioria, jovens na faixa dos 20 anos, com bombas de gás lacrimogênio e de efeito moral, dispersando os participantes do protesto em direção à Avenida da Consolação. Os manifestantes jogaram cestas de lixo. "Há muita fumaça e correria", relatou o repórter Vasconcelo Quadros. O confronto durou cerca de 15 minutos, causando tensão entre os passantes e usuários do metrô, que ficaram presos na estação Consolação, entre as ruas Augusta e Haddock Lobo. (PROTESTO..., 2013). 
No dia seguinte, 7 de junho, um novo protesto do MPL - desta vez contando com 5 mil manifestantes, segundo os organizadores - foi mobilizado, principalmente através de um evento criado no Facebook e que teve virtualmente mais de 20 mil presenças confirmadas. Já nesta data, estava marcado, na mesma rede social, um protesto para o fim do mês que viria a ser, pra surpresa de seus próprios idealizadores iniciais, o ápice da Grande Onda; o debate em torno da presença dos partidos e a campanha para que estes não levassem suas bandeiras aos atos já tinham força; o lema premonitório era "Dia 20 o Brasil vai parar" - dificilmente quem o escreveu fazia ideia de o quanto estava certo. As imagens de violência no dia anterior (06), que circularam pela grande imprensa e sobretudo pelas redes sociais, geraram, num curto período de menos de 24 horas, uma surpreendente mobilização. O movimento, a partir daí, demonstraria um vigor novo e incomum.

Pelas imagens que circularam nas mídias impressa e eletrônica, pudemos verificar que já nesse momento ganhavam visibilidade os grupos de "mascarados" que praticavam boa parte das ações "radicalizadas", ações que foram o impulso inicial para dar visibilidade aos protestos e que prosseguiram sendo um dos grandes trunfos da espantosa mobilização em torno dos movimentos, numa simbiose entre os "radicais" e a mídia do espetáculo, a despeito da reprovação pública dos próprios dirigentes do movimento e das expressões de uma crescente massa de manifestantes que chegou a fazer da frase "Sem violência" seu programa nos protestos, num processo de autorreferência de que voltaremos a falar.

Em meio à massa de manifestantes, via-se a presença de organizações políticas tradicionais em protestos de ruas no Brasil, todas de esquerda, com notório destaque ao que se costuma chamar de extrema esquerda - partidos que fazem oposição aos governos petistas, como PSTU e PSOL. A liderança do MPL, contudo, era inegável. Apesar das divergências quanto à avaliação dos governos federal e municipal, o centro político das manifestações era a rejeição ao aumento das passagens. Palavras de ordem contra a gestão do prefeito Haddad eram comuns e não encontravam grande oposição. Além do apelo das cenas e da crescente repercussão 
que os movimentos passaram a ter nas redes sociais, um fator político pesou na até então inédita atenção que os movimentos estudantis teriam, do dia 6 em diante, por parte da grande imprensa: um dos principais alvos dos protestos não podia deixar de ser o recém-empossado prefeito da maior cidade do país, o petista Fernando Haddad.

\section{O MPL E OS MOVIMENTOS SOCIAIS NA ERA DA INTERNET}

Ao longo das duas últimas décadas, sempre que aumentos no preço das passagens ou ameaças à meia-passagem estudantil vieram à tona, em praticamente todas as grandes cidades do país, houve intensos protestos estudantis, comumente organizados por entidades representativas dos estudantes. Muito mais do que por serem em si inéditos, seu aparente ineditismo se deve principalmente ao caráter daquilo a que Guy Debord chamou de "espetáculo", que expressa "o discurso ininterrupto que a ordem atual faz a respeito de si mesma" (DEBORD, 1997, p. 20), numa autorreferência constante que faz desacreditar a validade do que tenha ocorrido à margem do espetáculo. Exemplo disto é que, de 2012 até então, as manifestações ligadas ao transporte público haviam sido ininterruptas, em todo o país praticamente, mas - ausentes do noticiário, ou dignas de pequenas notas reprovatórias - criou-se o clima de um gigante que teria acordado, de uma massa estudantil que teria voltado às ruas, das quais sequer saiu.

Estes movimentos estudantis de 2013 tinham, contudo, uma particularidade, que em si também não era de todo inédita. Majoritariamente, os estudantes que foram às ruas contra o aumento das passagens em São Paulo o fizeram sob a liderança de uma organização nova, o MPL. Conforme atesta em sua Carta de Princípios, o:

Movimento Passe Livre é um movimento horizontal, autônomo, independente e apartidário, mas não antipartidário. A independência do MPL se faz não somente em relação a partidos, mas também a ONGs, instituições religiosas, financeiras etc. (MPL, 2013). 
Parece ser claro que o MPL surge em alternativa a entidades tradicionais como a UNE, postulando formas de organização que diferem das estruturas representativas do movimento estudantil que marcou a oposição aos governos de FHC e trazendo também uma estrutura organizativa própria.

O MPL se constitui através de um pacto federativo, isto é, uma aliança em que as partes obrigam-se recíproca e igualmente e na qual os movimentos nas cidades mantêm a sua autonomia diante do movimento em nível federal, ou seja, um pacto no qual é respeitada a autonomia local de organização. (MPL, 2013).

De fato, existiam células ou representações do MPL em diversos estados brasileiros, mas em nenhum deles o movimento era majoritário como em São Paulo. Em nenhuma outra grande cidade, o MPL teve o protagonismo e a força que teve em São Paulo.

Certa tendência interpretativa, que busca dar conta de como esses movimentos teriam alcançado as proporções que vimos nos Movimentos de Junho, aponta para o entendimento geral de que os movimentos ocorridos no Brasil, de alguma forma, foram influenciados pelo ambiente internacional de mobilizações, que derrubaram governos, mudaram regimes e mobilizaram milhões em dezenas de países. Um passo inicial desta abordagem deve ser, portanto, analisar e delimitar a influência destes movimentos globais nos eventos que aqui se estudam, expor e criticar possíveis semelhanças que contribuam com o esforço de compreender os Movimentos de Junho. Assim, lançaremos mão da obra de Manuel Castells (2013a; 2013b) surge como aporte para explicitar o que representam esses movimentos, pois que sua visão se aproxima muito daquilo que os próprios movimentos pensam de si. Tanto na recepção que seus textos tiveram, quanto em seu próprio comportamento, transparece a profunda identificação desse autor com o objeto de sua análise.

Na edição brasileira de seu Redes de indignação e esperança: movimentos sociais na era da internet, o sociólogo espanhol publicou um posfácio acerca dos Movimentos de Junho. Sua análise, em resumo, insere os movimentos brasileiros no mesmo contexto 
das múltiplas mobilizações populares que pululam nos últimos anos ao redor do mundo. Assim:

Aconteceu também no Brasil. Sem que ninguém esperasse. Sem líderes. Sem partidos nem sindicatos em sua organização. Sem apoio da mídia. Espontaneamente. Um grito de indignação contra o aumento do preço dos transportes que se difundiu pelas redes sociais e foi se transformando no projeto de uma vida melhor [...]. (CASTELLS, 2013a, p. 178).

Ainda que breve - pouco menos de cinco páginas -, seu posfácio reflete uma linha de análise sobre os Movimentos de Junho que tem se fortalecido pela crescente repercussão dos movimentos contestatórios que surgem por todo o mundo nesta década. Castells (2013a) reforça a importância da questão do transporte público nas motivações dos protestos no Brasil: "Passe Livre. Porque a mobilidade é um direito universal, e a imobilidade estrutural das metrópoles brasileiras é resultado de um modelo caótico de crescimento urbano produzido pela especulação imobiliária e pela corrupção municipal" (CASTELLS, 2013a, p. 178). E acrescenta, em sua crítica, que é um "modelo centrado no crescimento a qualquer custo, ainda que, no caso do Brasil, acompanhado de uma redução da pobreza e de políticas sociais redistributivas" (CASTELLS, 2013a, p. 179), criticando o "modelo neodesenvolvimentista, como o chinês", a qualidade e as estratégias da educação e dos serviços de saúde.

Apontando para uma reação da "classe política" que se daria em conformidade com o que ocorreu no resto do mundo, destaca um certo ineditismo do caso brasileiro:

Pela primeira vez, desde que, em 2010, se iniciaram esses movimentos em rede em noventa países diferentes, a mais alta autoridade institucional declarou que "tinha a obrigação de escutar a voz das ruas". E fez com que seu gesto de legitimação do movimento fosse acompanhado da recomendação, seguida pelas autoridades locais, de se anularem os aumentos das tarifas de transporte. (CASTELLS, 2013a, p. 180). 
Apesar de dar a impressão de que, algumas vezes, o autor desempenha um papel de porta-voz do objeto que estuda, dizendo o que dele se espera ouvir - como em suas afirmações superficiais do significado da PEC 37 e de uma possível reforma política que traga fórmulas que "limitem a partidocracia" -, suas análises trazem grande aporte para a compreensão dos movimentos que estudamos. Isso porque ele discorreu, mais ou menos acertadamente, acerca do papel desempenhado por novas formas de comunicação e interação sociais, tidas por ele como a realidade inédita que possibilitou a erupção de movimentos com as características que observa nos atuais. Sua interpretação de movimentos como a Primavera Árabe, o Occupy Wall Street, os Indignados na Espanha, entre outros, expõe claramente a visão que tem acerca dos movimentos de transformação social em nosso século. Por isso, nos deteremos mais demoradamente sobre sua interpretação desses fenômenos, a fim de compreender em que se assemelham aos movimentos que estudamos.

Castells (2013a) traça um panorama dos movimentos que têm seu início com as revoltas populares na Islândia e na Tunísia, perpassando toda a Primavera Árabe, os Indignados da Espanha e o Occupy Wall Street. Segundo tal análise, esses novos agentes sociais do século XXI trariam consigo a expressão de profundas mudanças na dinâmica social e, consequentemente, nas relações de poder. Para o autor, esses movimentos se caracterizam essencialmente por surgir naquilo a que chama de "ambiente livre da internet", por se manifestar pela ocupação dos espaços públicos e por ser ontologicamente incompatíveis com lideranças formais e programas ou plataformas políticas.

O novo espaço público - "espaço da autonomia", cenário dos novos movimentos sociais - é realizado na interseção entre os espaços virtual e físico. É no espaço virtual que os movimentos nascem, da indignação e da revolta de um agente, ou diversos, que, através das redes sociais, consegue estabelecer vínculos de solidariedade com contingentes cada vez maiores. Subsequentemente, os movimentos na internet se articulam aos movimentos sociais externos a ela para "organizar a ocupação do espaço público". O autor aponta que, além de dinamizá-lo - ampliando o alcance e 
a velocidade das informações -, a internet favorece esse tipo de movimento, porque fornece um espaço seguro, onde a indignação individual pode somar-se a outras e, como ele mesmo diz repetidas vezes, "superamos o medo quando estamos juntos". Assim, eles surgem no espaço seguro da internet e das redes de comunicação sem fio, através de apelos que se difundem em redes sociais preexistentes. Isso tem maiores implicações, pois "a tecnologia não determina os movimentos sociais [...]. Porém, as redes da internet e de telefonia celular não são apenas ferramentas, mas formas organizacionais, expressões culturais e plataformas específicas para a autonomia política" (CASTELLS, 2013a, p. 82). A rapidez e a interatividade propiciadas pelas redes sociais na internet favorecem o "processo de ação coletiva, enraizado na indignação, propelido pelo entusiasmo e motivado pela esperança" (CASTELLS, 2013a, p. 19).

Os movimentos se manifestam pela ocupação de espaços públicos, em que se criam laços de identidade e solidariedade. Esses espaços ocupados, com efeito, estão carregados da força simbólica da tomada de espaços do poder constituído, de tal forma que as comunidades que daí surgem engendram novas formas de debate e deliberação, constituindo uma alternativa política à rede de poder, num ensaio da nova democracia que seria o legado desses movimentos.

Os novos movimentos sociais são avessos à hierarquia e tendem a ser participativos, em proporção direta ao potencial interativo e autoconfigurável da comunicação em que se fundam.

Os movimentos são entendidos por Castells (2013a) como redes de contrapoder, que se articulam e buscam desarticular as redes de poder constituídas. O poder seria aqui "exercido por meio da coerção (o monopólio da violência, legítima ou não, pelo controle do Estado) e/ou pela construção de significado na mente das pessoas, mediante mecanismo de manipulação simbólica" (CASTELLS, 2013a, p. 10). O autor afirma que coerção e intimidação "são mecanismos de imposição da vontade dos que controlam as instituições da sociedade", mas acrescenta que "a construção de significado na mente das pessoas é uma fonte de poder mais decisiva e estável" (CASTELLS, 2013a, p. 10). Ele postula que 
redes de poder formam "metarredes" que, através de sua coordenação, adquirem a "capacidade de definir as regras e normas da sociedade mediante um sistema político que responde basicamente a seus interesses e valores" e, consequentemente, a rede de poder representada pelo Estado tem papel central na articulação do poder na sociedade, porque o Estado possui esta capacidade de articular e mobilizar as demais redes de poder, como as mídias, o poder financeiro e o poder militar, por exemplo. A "alternância de poder", entendida como a "capacidade de conectar duas ou mais redes diferentes no processo de construir o poder para cada uma delas em seus respectivos campos", surge como o mecanismo pelo qual as redes distintas exercem o poder na sociedade conjuntamente (CASTELLS, 2013a, p. 13). Os movimentos sociais surgem como fontes da mudança à medida que se constituem em um contrapoder.

Se o poder é exercido programando-se e alternando-se redes, então o contrapoder, a tentativa deliberada de alterar as relações de poder, é desempenhado reprogramandose as redes em torno de outros interesses e valores, e/ou rompendo as alternâncias predominantes, ao mesmo tempo que se alteram as redes de resistência e mudança social. (CASTELLS, 2013a, p. 13-14).

$\mathrm{Na}$ reconstrução dos diversos movimentos que constam em seu livro, o autor procede à análise de eventos que ilustram sua teoria dos movimentos sociais em rede. Ele destaca que o que lhe interessa é estudar como ocorrem as transformações sociais e aponta que elas são, ao longo da história, fruto da ação dos movimentos sociais, que eclodem com maior força quase sempre quando há grande depreciação da qualidade de vida das pessoas. O que interessa aqui é principalmente saber como, na visão de Castells (2013a), revoltas localizadas podem - com o aporte providencial da internet - mobilizar agentes e demandas diversas em torno de um único movimento de contestação.

A análise dos movimentos estudantis de 2013 e de sua principal liderança nos demonstra que a força da mobilização pela internet e pelos meios de comunicação se fez notar mais vivamente a 
partir do dia 13 de junho, quando surge a Grande Onda; até então, essa mobilização era mais um instrumento organizacional que um movimento "espontâneo". E é a partir daí que as ideias de Redes de indignação e esperança têm mais a contribuir com o presente debate.

Não cremos que os movimentos estudantis de 2013 tenham origem no mesmo tipo de fenômeno que originou a Grande Onda. Eles são - em verdade - a continuação mais ou menos fiel dos movimentos estudantis históricos e, ao contrário do que supôs Castells (2013a), não surgiram espontaneamente da internet, mas foram mobilizados - com o reforço da internet - por uma organização, o MPL, que possui, inclusive, células em diversas escolas e universidades de São Paulo (MPL, 2013). O que é inegável, contudo, é que essa organização se inspira e orienta por métodos e valores absorvidos das experiências internacionais de contestação, sobretudo dessas que Castells (2013a) analisa. No caso brasileiro, porém, como vemos pelas redes (para usar um termo em voga) que ligam o MPL a organizações políticas tradicionais, essa influência sofreu significativas pressões locais e foi adaptada. Isso se evidencia sobremaneira na decisão de eleger um alvo específico das políticas públicas e de agir no sentido de pressionar o Estado a ouvir e atender as demandas expressas pelo movimento, nisto destoando do tipo ideal de movimento proposto por Castells (2013a), como veremos.

Para esse autor, os protestos têm origem na reação de indivíduos à determinada situação; a partir da indignação, formam-se redes que, ao unir as pessoas, lhes levam a superar o medo.

No plano individual, os movimentos sociais são emocionais. A insurgência não começa com um programa ou uma estratégia política. Isso pode vir depois, quando surge a liderança, de dentro ou de fora do movimento, para fomentar agendas políticas, ideológicas e pessoais que podem ou não relacionar-se às origens e motivações dos participantes do movimento. (CASTELLS, 2013a, p. 18).

Em todos os casos, o autor aponta um momento simbólico que pode representar a indignação coletiva e percorrer as redes 
da internet, mobilizando outras redes na sociedade. Assim, o autoimolamento de um vendedor de 26 anos, chamado Mohamed Bouazizi, filmado por um parente e difundido pela rede mundial de computadores, é apontado como o estopim da revolução na Tunísia. Este gesto dramático teria servido como reforço à indignação popular, que então superaria o medo levando à ação. As motivações emocionais dos indivíduos possuem aqui grande relevância. Ao teorizar sobre os movimentos, o autor afirma que "foi basicamente a humilhação provocada pelo cinismo e pela arrogância das pessoas no poder, seja ele financeiro, político ou cultural, que uniu aqueles que transformaram medo em indignação, e indignação em esperança de uma humanidade melhor" (CASTELLS, 2013a, p. 08).

A Revolução das Panelas, na Islândia, serviria de modelo a movimentos subsequentes por ter gerado uma profunda alteração do funcionamento democrático nacional, engendrando, inclusive, uma nova constituição que fortalece o poder de defesa da sociedade ante os grupos de interesses economicamente privilegiados. Foi também, em nossa opinião, uma experiência original de enfrentamento à crise estrutural do capital que busca reposicionar as relações de trabalho numa condição ótima de exploração, maximizando os lucros e sobrecarregando os trabalhadores com os ônus da crise que, desde 2008 - mas, de certa forma, desde a década de 1970 -, vem reorganizando o capital.

Castells (2013a) demonstra que os aspectos centrais, as características fundantes dos "movimentos sociais na era da internet", que já estavam presentes em suas origens na Islândia e na Tunísia, se acentuaram e caracterizaram a construção dos movimentos subsequentes analisados, como, por exemplo, a Revolução Egípcia, as Insurreições Árabes, os Indignados na Espanha e o Occupy Wall Street.

O autor discute se os movimentos em rede constituiriam um padrão emergente. Aponta que eles se fundam numa cultura da autonomia e da individuação que, possibilitadas e mesmo estimuladas pela internet, fornecem os elementos de uma nova forma de intervenção política. Além de reforçar que os movimentos se caracterizam por suas origens no mundo virtual, ocupando o espaço 
público no que chama de "espaços de autonomia", demonstra que os movimentos em análise não creditam confiança aos representantes e ao sistema representativo dominantes. Assim, apesar de uma notória dificuldade - ou desinteresse - em dialogar com organizações e instituições estabelecidas, os movimentos deixariam seu legado sendo eles mesmos, em sua prática de debate e deliberação em rede e nos acampamentos, o ensaio de uma nova forma de democracia. Os "movimentos sociais na era da internet", mais do que movimentos que pretendem mudar a sociedade, seriam movimentos que buscam novas formas de representação e a construção de uma nova democracia, mudando a realidade indiretamente, à medida que muda a mente das pessoas.

\section{CONSIDERAÇÕES FINAIS: OS LIMITES DOS MOVIMENTOS EM REDE E A GRANDE ONDA}

A desconfiança desses movimentos em relação à "classe política" e a sua rejeição ao modelo "estabelecido" de representação são considerados por Castells (2013a) algumas de suas marcas fundamentais. Numa comparação entre os novos movimentos e as formas tradicionais de representação, ele afirma que os movimentos "são talhados para o papel de agentes da mudança na sociedade em rede, num contraste agudo com as instituições políticas obsoletas herdadas de uma estrutura social historicamente superada" (CASTELLS, 2013a, p. 171). Noutro trecho, caracteriza o projeto político da "esquerda tradicional" como "visão de mundo fora de moda". No mesmo parágrafo, ele ainda esclarece bem a diretriz dos novos movimentos, dizendo que:

[...] ela realmente corresponde a duas tendências fundamentais: em primeiro lugar, a maioria das pessoas simplesmente não confia no processo político tal como está agora estruturado, de modo que só contam consigo mesmas; em segundo, o movimento é grande e forte porque une indignação e sonhos, ao mesmo tempo que evita a política tal como usualmente praticada. Essa é sua força e sua fraqueza. (CASTELLS, 2013a, p. 146). 
É claro e declarado que o autor inclui no mesmo rol das instituições que não merecem confiança tanto os governos e as instituições do capital, quanto os partidos da "velha esquerda". Ele propõe que, em oposição aos "métodos atrasados" das organizações revolucionárias tradicionais - métodos que refletiriam e reproduziriam a opressão -, os novos movimentos da era da internet agem no sentido de desenvolver experiências de democracia e de novas formas de expressão e representação que, por si, servem como substituto aos projetos universalistas de transformação da sociedade, na medida em que operam no âmbito mais importante e decisivo: a mente das pessoas, onde a prática dos novos movimentos inculca novos valores. Para o autor, essa "característica essencial dos movimentos observados resulta diretamente de uma de suas causas: a rejeição dos representantes políticos pelos representados, depois que se sentiram traídos e manipulados em sua experiência com a política instituída" (CASTELLS, 2013a, p. 162 - 163).

Ao longo de sua obra, Castells (2013a) se conduz, cada vez mais, como um candidato a porta-voz dos movimentos. Nesse ofício, transforma em virtudes as limitações históricas dos "movimentos em rede". Apesar de seu inegável esforço teórico em postular a construção de novos valores, que por si formariam uma geração destinada à ruptura com o status quo, tanto a indefinição deste status quo quanto daquilo que seria a suposta ruptura radical apontam para um movimento autorreferencial. A leitura de seu estudo redunda numa compreensão geral de que, pesados prós e contras, os novos métodos superariam os da velha esquerda, tornados antiquados pelo novo mundo que surge.

A concepção política dos novos movimentos sociais, tal como são apresentados por Castells (2013a), vai no sentido oposto ao da grande força transformadora representada pelas organizações revolucionárias da primeira metade do século XX. Essas organizações, segundo Hobsbawm (2011), foram portadoras do projeto socialista e, mesmo contando com reduzidos contingentes, conseguiram moldar em grande parte a política daquele século pela força de seu empenho, disciplina e sacrifício. Mesmo reconhecendo que amplos movimentos de massa sem organicidade política e projetos claros surgiram na Rússia de 1917, Hobsbawm (2011) faz 
lembrar que, sem a presença ativa das organizações proletárias nos locais de trabalho, os "sovietes", e sem a presença de uma liderança política portadora de um projeto nacional popular, como foram os bolcheviques, os rumos da mobilização seriam incertos e a Revolução de 1917, improvável.

Movimentos espontâneos não são novidade na história. Desde o século XIX, a concentração de uma crescente população urbana, desprovida dos meios necessários para a produção de sua existência e submetida a condições excruciantes de trabalho visando a uma rápida acumulação de capital, fez surgir - sobretudo nos países de capitalismo mais desenvolvido, a exemplo da Inglaterra - intensos movimentos sociais. Esses movimentos passaram a ter maior relevância e efetividade à medida que incorporavam a política em seus objetivos e métodos, processo do qual o cartismo é uma testemunha convincente, tal qual um raro fóssil do elo perdido da evolução dos movimentos de emancipação da classe trabalhadora (HOBSBAWM, 2011, p. 88-97). Compreendendo a longa trajetória dos movimentos sociais, vê-se que a negação das suas formas "tradicionais" de movimento vai além da simples negação de forma e método. O próprio projeto transformador da sociedade é negado. Ocorre com a esfera da ação política e a "nova cultura" aquilo que Ellen Wood (2011) denunciara em relação à economia e à politica, artificialmente separadas na estrutura das sociedades capitalistas:

Sob este aspecto o capitalismo difere das formas pré-capitalistas porque estas se caracterizam por modos extaeconômicos de extração de mais-valia, a coação política, legal ou militar, obrigações ou deveres tradicionais etc, que determinam a transferência de excedentes para um senhor ou para o Estado por meio de serviços prestados, aluguéis, impostos e outros. (WOOD, 2011, p. 35). ${ }^{3}$

3 Wood usa de forma muito particular o conceito de "mais-valia". A título de registro, salientamos que para nós tal conceito se restringe à forma de expropriação dos excedentes de produção no capitalismo, o que, de forma alguma, invalida ou diminui a força das ideias de Wood, quando analisa as formas pelas quais, no capitalismo, a exploração econômica adquiriu relativa autonomia em face da política, processo no qual a política teve sua abrangência restringida e passou a submeter-se à dinâmica da economia. 
A luta política surge então - num fenômeno de intensificação da separação artificial das esferas - como alheia aos processos políticos "instituídos", ou seja, à luta política concreta em torno da construção e direção do Estado. Nas palavras de Slavoj Zizek (2013): "Não votamos em quem deveria ser o dono do quê, nas relações dentro de uma fábrica etc. Tudo isso é deixado para os processos de fora da esfera política. A ideologia dominante mobiliza aqui todo o seu arsenal para nos impedir de chegar a esta conclusão radical" (ZIZEK, 2013, p. 107). Agora, se trata de alijar da política a própria ação política contestadora. Não se leva em consideração que "o Estado apresenta uma ossatura material própria que não pode de maneira alguma ser reduzida à simples dominação política" (POULANTZAS, 2000, p. 12), que esta é historicamente baseada nas relações de produção vigentes e que as constitui. A separação suposta entre relações de produção e dominação política:

não nos deve levar a crer em real exterioridade do Estado e da economia, como se o Estado só, do exterior, interviesse na economia. Esta separação é a forma precisa que encobre, sob o capitalismo, a presença constitutiva do político nas relações de produção e, dessa maneira, em sua produção. (POULANTZAS, 2000, p. 18).

Assim, não apenas se omitem os vínculos intrínsecos de relações de produção e poder político, como extrapolam esta tendência desvinculando da disputa pelo poder político "o projeto de uma vida melhor".

A abrangência de tais movimentos, na conformação postulada por Castells (2013a), representa um desvio de curso no processo histórico em que as classes subalternas elevam o nível de sua ação política, transformando seu descontentamento espontâneo, e até mesmo reativo, em projeto nacional, político e transformador. $\mathrm{Na}$ ausência de programas e plataformas, fica fácil - como veremos adiante - para os detentores do poder e dos meios de comunicação construir por cima o sentido e a pauta das mobilizações. Os movimentos - apesar dos esforços de Castells (2013a) em apresentar-lhes de forma distinta - não pecam por serem inócuos, mas por 
tenderem ao conservadorismo, na medida em que negam alternativas que promovam profundas mudanças estruturais da sociedade ou "projetos universalistas", se preferirmos. E como escrevia Gramsci (2007), num trecho que muito nos diz a este respeito:

A grande política compreende as questões ligadas à fundação de novos Estados, à luta pela destruição, pela defesa, pela conservação de determinadas estruturas orgânicas econômico-sociais. A pequena política compreende as questões parciais e cotidianas que se apresentam no interior de uma estrutura já estabelecida em decorrência de lutas pela predominância entre as diversas frações de uma mesma classe política. Portanto, é grande política tentar excluir a grande política do âmbito interno da vida estatal e reduzir tudo a pequena política. (GRAMSCI, 2007, p. 21).

Celso Frederico (2013), analisando o contexto cultural e político dos Movimentos de Junho, é da mesma opinião:

Todos queriam ser protagonistas; ninguém mais queria ser "representado". Sem a presença de partidos - que existem para universalizar as reivindicações - tais manifestações correm o risco de se dispersar num conjunto infinito de reivindicações particularistas e, o que é pior, de serem pautadas pelo novo partido da sociedade do espetáculo: o "partido da mídia". (FREDERICO, 2013, p. 248).

Concepção similar à de Castells (2013a) está implícita em Maria da Glória Gohn (2010), para quem, nas últimas décadas, "a realidade se alterou, novíssimos sujeitos entraram em cena, novas formas de ação social coletiva emergiram - muitas vezes denominadas apenas 'mobilização social' - novas categorias de análise foram criadas e as teorias se ampliaram" (GOHN, 2010, p. 10 - grifo nosso). A despeito de que a realidade tenha se alterado, como é de se esperar que seja em todas as épocas, a autora também não consegue explicar como se deu a passagem para o momento em que:

o Estado, objeto central de investigação de uma grande parcela de cientistas sociais, passou, no plano da realidade concreta, com a globalização, a ser deslegitimado, criticado, com destaque para a perda de 
sua importância como agente regulador de fronteiras nacionais, controles sociais etc. Ocorreu um deslocamento de interesse para a sociedade civil, e nesta os movimentos sociais são citados como uma das ações sociais por excelência. (GOHN, 2010, p. 11).

Ao deslocamento do Estado para a periferia das relações de poder corresponderia, por lógica, o deslocamento das lutas políticas, objeto de preocupação relegado àqueles que, "mais idealistas, afirmam que os movimentos não teriam realizado o papel a eles atribuído de transformadores de relações sociais, de agentes do processo de mudança social" (GOHN, 2010, p. 11). Assim, surge como natural o processo político bem descrito na seguinte passagem: "Na atualidade, muitos dos novíssimos movimentos, ou ações civis denominadas movimentos, não têm mais o universal como horizonte, mas sim o particular, os interesses imediatos, o direito de sua categoria ou grupo social" (GOHN, 2010, p. 12).

Salientamos, contudo, que a crítica aqui não segue no sentido de propor uma identificação imediata e necessária entre forma e conteúdo. O problema surge quando a forma é tradução e legitimação da exclusão de certos conteúdos, como ocorre com a exclusão da grande política do debate dos "movimentos em redes". Essa identificação, mais circunstancial que ontológica, não exclui dos movimentos sociais portadores de projetos universalistas e transformadores a obrigação de refletir e desenvolver suas formas organizativas. Em fase histórica caracterizada pela ampliação da sociedade civil e avanço do domínio ideológico, o debate de ideias deve ser aprofundado, não sufocado pelo discurso de autoridade nem pela tradição. A horizontalidade dos movimentos que ora criticamos não é em si um dado negativo, podendo mesmo expressar uma possibilidade de renovação e reafirmação de ideais revolucionários, desde que incorporem o debate e os projetos da grande política. É inegável que os movimentos transversais e plurais da Grande Onda são muito mais atrativos e formalmente democráticos que os atos rígidos e repletos de carros-de-som e discursos intermináveis de lideranças pouco ou nada conhecidas pelos manifestantes. Perdem, contudo, seu caráter democrático ao ser vítima fácil da manipulação midiática. A superação desse 
impasse talvez esteja no fortalecimento dos movimentos sociais universalistas, através de uma rede de organizações que, na sociedade civil, incorporem parcelas cada vez mais extensas da sociedade em um debate inclusivo e através de práticas que, ao mesmo tempo, preservem a capacidade de intervenção política efetiva e promovam a solidariedade e o debate, quem sabe avançando no sentido da "reforma intelectual e moral" de que falava Gramsci.

Retornando às ideias de Redes de indignação, salientamos o acerto de Castells (2013a) ao ver, nas ferramentas das tecnologias de informação e comunicação (TICs), potencializadores da mobilização urbana. Contudo, sua análise incorre num fenômeno mais geral a que Mauro Luis Iasi (2013) associou o culto fetichizado dos meios, tão comuns nas interpretações correntes sobre o papel das redes sociais nas dinâmicas e estruturas da sociedade.

Ao contrário do que alguns pensam, o problema não é somente uma questão de organização e comunicação. "Ah, se colocarmos as palavras certas que ao ver os desperte, se marcarmos em um local ou horário mais adequado, se encontrarmos a forma de lhes falar diretamente, se eles nos escutassem", dizemos a nós mesmos num misto de preocupação política e culpa cristã. (IASI, 2013, p. 44).

Tentar explicar o processo histórico por sua manifestação aparente, desprezando as causalidades das quais os movimentos com a dimensão dos que vimos em junho não podem fugir, ao que nos parece, é uma falha importante de Castells (2013a). A deflagração da Grande Onda, a partir dos movimentos estudantis de 2013, não se dá principalmente nem pelo crescimento natural destes, nem pelo apelo das redes sociais da internet em reação à violência do dia 13 de junho (apesar de ambos os fatores terem sua importância). Para produzir tal efeito, era necessária a entrada em cena das forças políticas que disputam a hegemonia na sociedade brasileira: de um lado, as então forças governistas, lideradas pelo Partido dos Trabalhladores (PT) e pelos movimentos sociais a ele ligados, como a Central Única dos Trabalhadores (CUT) e o Movimento dos Trabalhadores Rurais Sem Terra (MST); de outro lado, as oposições conservadoras lideradas pelo Partido da Social 
Democracia Brasileira (PSDB) e pelos Democratas (DEM), que tiveram na grande mídia seu instrumento principal de mobilização.

A inserção destes grupos políticos no centro da disputa pelos rumos dos Movimentos de Junho se fez notar pelo contraste, a partir da Grande Onda, entre uma "pauta popular organizada de baixo para cima nos primeiros dias, na qual era central a questão da tarifa de transporte [...] [e] De outro, uma pauta que veio de cima para baixo. Essa era a pauta de massa." (SECCO, 2013, p. 72 - colchetes nossos). A isso, cabe acrescentar outra consideração: "As possibilidades emancipatórias da internet convivem com sua colonização pelas atividades comerciais, pela presença agressiva de internautas profissionais a serviço de partidos, empresas etc., e, hoje sabemos, por uma implacável vigilância por parte dos Estado Unidos" (FREDERICO, 2013, p. 248 - 249).

A nosso ver, duas das características centrais dos novos movimentos - segundo Castells (2013a), a ausência de lideranças e a ausência de plataformas ou programas políticos - nos remetem à forma de organização e de representação ideológica da sociedade burguesa em sua etapa atual, o capitalismo de acumulação flexível (SPINELLI; LYRA, 2007). Sua manifestação tardia nos movimentos sociais brasileiros tem origem no peculiar percurso das ideias pósmodernistas no Brasil.

O ideário pós-modernista surge no país inicialmente como um movimento cultural que tem sua recepção prioritariamente nos círculos acadêmicos e através de revistas culturais especializadas que traduziam a certo público nacional, ávido por manter-se atualizado, as tendências e os debates dos países centrais do capitalismo. Assim, ao longo da década de 1980, o pós-modernismo entre nós "assumiu o caráter de uma questão que dizia respeito apenas a especialistas" (EVANGELISTA, 2007, p. 185).

João Emanuel Evangelista (2007) aponta ainda dois fatores determinantes na recepção das ideias pós-modernistas no Brasil: primeiro, "não podemos esquecer da existência de uma tendência com longa e enraizada tradição histórica na sociedade brasileira, caracterizada pela imitação obsessiva e por aquilo que alguns denominam de mazombismo de nossa intelectualidade" (EVANGELISTA, 2007, p. 29); segundo, a discussão sobre o 
pós-modernismo se deu inicialmente em círculos especializados de intelectuais sensíveis a suas ideias, sobretudo estéticas. Quanto ao primeiro ponto, salta aos olhos a prevalência nos movimentos esparsos, candidatos a herdeiros e continuadores das Jornadas de Junho, de hábitos e costumes dos movimentos dos países centrais do capitalismo - Castells (2013a, p. 140) chega a reproduzir uma tabela com gestos que foram desenvolvidos no Occupy Wall Street e que hoje se tornaram banais nas plenárias dos movimentos autonomistas brasileiros, a exemplo da habitual salva de palmas com apenas dois dedos (algo parecido com o sinal vulgar para dinheiro).

Nos anos 1990, a derrota das forças progressistas reunidas em torno de Lula na eleição de 1989, o arrefecimento das esperanças transformadoras e o refluxo dos movimentos sociais -- no contexto da autodissolução da União Soviética - compuseram um quadro propício à propagação no Brasil de um ethos pós-modernista que teria grande influência na intelectualidade, marcando nossa teoria social contemporânea (EVANGELISTA, 2007). Contudo, ao longo da década de 1990 - apesar da crescente força das ideias pósmodernistas na esquerda nacional - foi possível uma expressiva unidade dos movimentos sociais brasileiros, que, acossados por sucessivos governos neoliberais, viram em entidades e movimentos, como o MST, a CUT e a UNE, lideranças e referências no processo de mobilização social e de enfrentamento político.

A vitória do bloco liderado pelo PT em 2002 e a política desenvolvida pelos sucessivos governos lulistas afloraram a desesperança em setores da esquerda radical, mais propícios ao pensamento social pós-modernista.

Os protestos estudantis de 2013 eram, sobretudo, liderados por organizações dos ditos "novos movimentos sociais", que, a exemplo daqueles analisados por Castells (2013a), possuem forte rejeição a lideranças e programas políticos universalistas e somam-se ao conjunto de novos movimentos sociais brasileiros centrados em questões específicas e políticas de identidade. Portanto, aqueles movimentos de 2013 não podiam escapar de trazer em si os caracteres das organizações que lhes deram vida. 
Evangelista (2007) repara que a teoria social pós-modernis$\mathrm{ta}^{4}$ tem como premissa, explícita ou implicitamente, uma suposta ruptura da sociedade capitalista moderna e o advento de uma sociedade pós-industrial.

Nessas sociedades pós-industriais, o Estado e as formas políticas teriam também sofrido uma profunda mudança. Com a fragmentação da sociedade e a desmaterialização da produção, desapareceriam as antigas contradições sociais de natureza estrutural e os sujeitos políticos universais, como as classes sociais, que atuavam com o objetivo de conquistar ou manter o poder político centralizado no Estado moderno. (EVANGELISTA, 2007, p. 177).

Eis a premissa necessária do pensamento de Castells (2013a) quando fala da "estrutura social historicamente superada" em que se baseariam os movimentos políticos tradicionais, igualmente superados.

A reificação da realidade social e a consequente transformação dos processos políticos em espetáculos desprovidos de essência, em fenômenos autocontidos e autoexplicáveis, sem determinações históricas, levou muitos críticos a crer que os Movimentos de Junho poderiam ir em qualquer direção, chegar a qualquer resultado a que a manifestação espontânea de descontentamento pudesse levar. Ainda hoje, órfãos dos Movimentos de Junho esperam a grande mudança, a revolução sem líderes que mudará de uma vez por todas a forma como se faz política. Como diz Evangelista (2007), "as disputas no campo político passariam a ser regidas pela lógica da política do espetáculo para as grandes massas." E, assim como cremos ter ocorrido nas interpretações correntes dos Movimentos de Junho, a "busca do convencimento pela argumentação racional e pela apresentação de projetos políticos, característica da política na modernidade, teria dado lugar à sedução das imagens no cenário midiático de massas da política pós-moderna" (EVANGELISTA, 2007, p. 177).

4 Para uma exposição crítica do pensamento de um dos principais expoentes desta corrente, ver Evangelista (2007, p. 75-118). 
Na teoria social pós-modernista, seguindo nossa interpretação das ideias de Evangelista, as "classes sociais e lutas de classes teriam sido deslocadas como suporte estrutural da política e do poder de Estado. Surgem em seu lugar os movimentos sociais" (EVANGELISTA, 2007, p. 178). Esse pressuposto está por trás da concepção de intelectuais como Castells (2013a). Nesta concepção, a transformação da sociedade pela disputa do poder político ficou no passado. Apenas mudanças pontuais, resignadas aos marcos do mercado, são possíveis. O Estado, de objetivo a ser conquistado para promover a transformação radical da sociedade, se torna um empecilho que deve ser contido e se limitar a garantir os direitos humanos e a liberdade (no mundo do capital). Desta forma, "a esquerda pós-moderna aproxima-se das postulações neoliberais do Estado mínimo, cuja interferência nas relações entre indivíduos deve ser ao máximo limitada" e sua teoria social "vem reforçar o coro das qualidades divinas do mercado" (EVANGELISTA, 2007, p. 178-9). A negação da totalidade, dos "discursos universalistas" e, portanto, dos projetos universalistas baseados nas relações sociais, voltados à transformação estruturada da realidade social, a "recusa de um projeto político universalista que tome o capitalismo como um sistema dotado de lógica e realização totalizantes, é a pedra de toque do pensamento pós-moderno" (EVANGELISTA, 2007, p. 179). Assim, concordamos com a afirmação: "A despeito de certas manifestações e intenções contestatórias e radicais da esquerda pós-moderna, o pós-modernismo torna-se caudatário do movimento de consolidação da hegemonia do pensamento conservador" (EVANGELISTA, 2007, p. 178 - 179).

Tais características dos novos movimentos sociais de orientação pós-modernista, que lideraram os movimentos estudantis de 2013 até a eclosão da Grande Onda, facilitaram a ação de parcelas da mídia que atuaram no sentido de construir uma pauta de cima para baixo, dirigindo os movimentos em seu ápice, a partir de sua capacidade de agendamento e construção da opinião pública, bem estudada e fundamentada pela "hipótese da agenda setting" (WOLF, 1995). Os movimentos sem líderes e sem propostas definidas, que buscaram suceder a luta específica contra os reajustes das tarifas de ônibus, foram vítimas fáceis da manipulação e direção 
por parte da grande mídia, exatamente por negarem a totalidade concreta de um sistema econômico e social nunca antes tão totalizante. Na ausência de organizações "tradicionais" dos movimentos sociais e de projetos políticos claros pautados nas relações sociais, a grande mídia, a indústria da cultura, dirigiu o espetáculo. Cabe aqui o alerta de Ellen Wood (2011):

Não devemos confundir respeito pela plu-
ralidade da experiência humana e das lutas
sociais com a dissolução completa da causa-
lidade histórica, em que nada existe além da
diversidade, diferença e contingência, nenhu-
ma estrutura unificadora, nenhuma lógica de
processo, em que não existe o capitalismo e,
portanto, nem a sua negação, nenhum pro-
jeto de emancipação humana. (WOOD, 2011,
p. 225).

A negação da luta de classes é também a negação dos agentes capazes de implementar um projeto de transformação radical da realidade; circunscreve as lutas sociais aos limites da ordem estabelecida, sendo, portanto, um esforço ideológico conservador. A expansão capitalista e a cultura do consumo ameaçam as condições ambientais necessárias à sobrevivência de nossa espécie; a elevação da produtividade não é capaz de extinguir a fome e a miséria, reproduzindo as condições estruturais de exclusão de amplas parcelas da humanidade; a ideologia da concorrência e da meritocracia minam as bases da solidariedade social; as condições de trabalho seguem em precarização crescente, com acentuada perda de garantias e ganho de insegurança; enfim, o capitalismo avança sobre conquistas da civilização humana e não acena com soluções para os problemas que a afligem. Diante desse quadro, realça-se a lucidez de Wood (2011) quando diz que a "lição que talvez sejamos forçados a aprender de nossas atuais condições econômicas e políticas é que um capitalismo humano, 'social' e verdadeiramente democrático e igualitário é mais irreal e utópico que o socialismo" (WOOD, 2011, p. 225). É possível se iludir tanto superestimando as possibilidades de êxito quanto subestimando o impacto da derrota. 


\section{REFERÊNCIAS}

CASTELLS, M. Redes de indignação e esperança: movimentos sociais na era da internet. Rio de Janeiro: Zahar, 2013a.

CASTELLS, M. Dilma é a primeira líder mundial a ouvir as ruas. Istoé, São Paulo, 28 jun. 2013b. Disponível em: <http://www. istoe.com.br/assuntos/entrevista/detalhe/311021_ DILMA+E+A+ PRIMEIRA+LIDER+MUNDIAL+A+OUVIR+AS+RUAS+>. Acesso em: 30 jun. 2013.

DEBORD, G. A Sociedade do Espetáculo. Rio de Janeiro: Contraponto, 1997.

EVANGELISTA, J. E. Teoria social pós-moderna: introdução crítica. Porto Alegre: Sulina, 2007.

FREDERICO, C. Da periferia ao centro: cultura e política em tempos pós-modernos. Estudos Avançados, São Paulo, v.27, n.79, p. 239 - 255, 2013.

GITLIN, T. Mídias sem limites. Rio de Janeiro: Record, 2003.

GOHN, M. da G. Novas teorias dos movimentos sociais. 3. ed. São Paulo: Edições Loyola, 2010.

GRAMSCI, A. Cadernos do cárcere Vol. III. 3. ed. Rio de Janeiro: Civilização Brasileira, 2007.

HOBSBAWM, E. Como mudar o mundo: Marx e o marxismo, 1840-2011. São Paulo: Companhia das Letras, 2011.

IASI, M. L. A rebelião, a cidade e a consciência. In: MARICATO, E. et al. Cidades rebeldes: passe livre e as manifestações que tomaram as ruas do Brasil. São Paulo: Boitempo, 2013. p. 41 - 46.

MPL - Movimento Passe Livre. Carta de princípios. São Paulo: [s.n.], 2013. Disponível em: <http://saopaulo.mpl.org.br/>. Acesso em: 15 set. 2013 .

PASSAGENS de metrô, ônibus e trens de SP terão reajuste a partir de $1^{\circ}$ de junho. Folha de S. Paulo, São Paulo, 17 mai. 2013. Disponível em: <http://www1.folha.uol.com.br/ cotidiano/2013/05/1280252-passagens-de-metro-onibus-etrens-terao-reajuste-a-partir-de-1-de-junho.shtml> Acesso em: 22 jun. 2013. 
POULANTZAS, N. O Estado, o poder, o socialismo. 4. ed. São Paulo: Paz e Terra, 2000.

PROTESTO contra aumento de tarifa tem confronto com Tropa de Choque. Último Segundo, São Paulo, 06 jun. 2013. Disponível em: <http://ultimosegundo.ig.com.br/brasil/sp/2013-06-06/ manifestacao-contra-aumento-das-tarifas-de-onibus-temconfronto-com-a-pm.html>. Acesso em: 22 jun. 2013.

ROUSSEFF, D. Pronunciamento da Presidenta da República, Dilma Rousseff, em cadeia nacional de rádio e TV. Portal do Planalto, Brasília, 21 jun. 2013. Disponível em: <http://www2.planalto. gov.br/imprensa/discursos/pronunciamento-da-presidenta-darepublica-dilma-rousseff-em-cadeia-nacional-de-radio-e-tv $>$. Acesso em: 26 jun. 2013.

SECCO, L. As jornadas de junho. In: MARICATO, E. et al. Cidades rebeldes: passe livre e as manifestações que tomaram as ruas do Brasil. São Paulo: Boitempo, 2013. p. 71 - 78.

SPINELLI, J. A.; LYRA, R. P. Capitalismo de acumulação flexível e as categorias gramscianas. Cronos, Natal, v. 8, n. 2, p. 567 - 587, 2007.

WOLF, M. Teorias da Comunicação. 4. ed. Lisboa: Editorial Presença, 1995.

WOOD, E. M. Democracia contra capitalismo: a renovação do materialismo histórico. São Paulo: Boitempo, 2011.

ZIZEK, S. Problemas no paraíso. In: MARICATO, E. et al. Cidades rebeldes: passe livre e as manifestações que tomaram as ruas do Brasil. São Paulo: Boitempo, 2013. p. 101 - 108. 